\title{
A AVALIAÇÃO REVISITADA: NOVOS ESPAÇOS DO POLÍTICO E DO PEDAGÓGICO NA GESTÃO EDUCACIONAL
}

\author{
LA EVALUACIÓN REVISITADA: NUEVOS ESPACIOS DE LO POLÍTICO Y \\ PEDAGÓGICO EN LA GESTIÓN EDUCATIVA
}

\author{
THE EVALUATION REVISITED: NEW POLITICAL AND PEDAGOGICAL SPACES \\ IN EDUCATIONAL MANAGEMENT
}

\author{
Ana Cristina GHISLENI ${ }^{1}$ \\ Daianny Madalena COSTA ${ }^{2}$
}

RESUMO: O artigo analisa a abordagem do projeto político-pedagógico (PPP) da mantenedora de uma rede municipal no que tange à avaliação. A análise constrói-se com base nos conceitos de regulação e de qualidade, a partir de revisões documental e bibliográfica. Partindo-se de compreensões sobre as características e o contexto de elaboração do PPP, de uma rede municipal de educação. A análise articula conceitos e possibilita perceber um redimensionamento do lugar da avaliação externa, garantindo um espaço ampliado do político e do pedagógico na atuação da gestão educacional.

PALAVRAS-CHAVE: Avaliação externa. Educação básica. Projeto político-pedagógico. Gestão educacional.

RESUMEN: El artículo analiza el enfoque del proyecto político-pedagógico (PPP) del mantenedor de una red municipal en lo que se refiere a la evaluación. El análisis se basa en los conceptos de regulación y de calidad ya partir de revisiones documental y bibliográfica.. A partir de entendimientos sobre las características y el contexto de elaboración del PPP, el análisis a partir de los conceptos posibilita percibir un redimensionamiento del lugar de la evaluación externa, garantizando un espacio ampliado de lo político y del pedagógico en la actuación de la gestión educativa.

PALABRAS CLAVE: Evaluación externa. Educación básica. Proyecto político-pedagógico. Gestión educativa.

ABSTRACT: The article analyzes the approach of the political-pedagogical project (PPP) of the maintainer of a municipal network with respect to the evaluation. The analysis is based on the concepts of regulation and quality and from documentary and bibliographic reviews. Based on the understanding of the characteristics and context of the PPP, the analysis based on the

\footnotetext{
${ }^{1}$ Universidade do Vale do Rio dos Sinos (UNISINOS), Porto Alegre - RS - Brasil. Professora permanente no PPG Mestrado Profissional em Gestão Educacional. ORCID: <https://orcid.org/0000-0002-1877-8182>. E-mail: anacghisleni@gmail.com

${ }^{2}$ Universidade do Vale do Rio dos Sinos (UNISINOS), Porto Alegre - RS - Brasil. Professora permanente no PPG Mestrado Profissional em Gestão Educacional. ORCID: <https://orcid.org/0000-0001-7045-0259>. E-mail: daiannycosta@hotmail.com
}

RIAEE - Revista Ibero-Americana de Estudos em Educação, Araraquara, v. 14, n. 3, p. 956-972, jul./set., 2019. e-ISSN: 1982-5587. 
concepts makes it possible to perceive a re-dimensioning of the place of the external evaluation, guaranteeing an amplified space of the political and pedagogical in the performance of the educational management.

KEYWORDS: External evaluation. Basic education. Political-pedagogical project. Educational management.

\section{Introdução}

A cidade de Sapucaia do Sul, região metropolitana de Porto Alegre, capital do estado do Rio Grande do Sul, no extremo sul do Brasil, passou por um recente e interessante processo de reconstrução do projeto político-pedagógico da mantenedora. No que tange à avaliação, tal processo adquiriu nuances interessantes que nos dispomos a analisar aqui à luz da primazia do político e do pedagógico em detrimento das diretrizes pontuais das avaliações externas. Os conceitos de regulação (BARROSO, 2004; FREITAS, 2005, 2007; LIMA, 2012) e de qualidade (PERRENOUD, 1999; BALL, 2004) auxiliam na análise proposta, construída metodologicamente a partir de revisões documental e bibliográfica (COSTA, 2010; GHISLENI, 2015). O projeto político-pedagógico aqui focalizado caracteriza-se pela sua atualidade e caráter participativo (posto que elaborado com a escuta ampla da sociedade e finalizado no ano de 2018) e pela sua vinculação a uma proposta política com matizes social e pedagogicamente comprometidas com um trabalho mais coletivo entre os entes de um sistema municipal, em favor da construção de uma educação escolar mais cidadã . Tais características evidenciam-se no seu processo de elaboração, nas diretrizes do documento e nas escolhas consagradas no formato final.

\section{A reconstrução do projeto político-pedagógico}

No ano de 2016, teve início a pesquisa intitulada "Articulações entre a gestão educacional, o projeto político-pedagógico e o currículo escolar - reflexões necessárias”, junto à rede municipal de educação da cidade de Sapucaia do Sul. Concomitante ao processo que se instituía com a investigação, a sede da Secretaria Municipal de Educação passou a realizar um conjunto de encontros formativos com as equipes gestoras das escolas e de seus profissionais/assessores das unidades escolares acerca dos PPPs. Tal articulação culminou, em 2018 - após a reorganização dos documentos de todas as unidades escolares e uma consulta 
pública com a participação de representantes de toda a comunidade sapucaiense - na elaboração do projeto político-pedagógico da própria mantenedora, documento analisado por este artigo.

Em 2017, após terem ocorrido as formações acerca do PPP, que serviram como preâmbulo para o a reconstrução dos projetos nas escolas, teve início a proposta de elaboração de uma "Carta de Princípios" da/para a rede municipal, com o objetivo de contribuir para a viabilização da reorganização de seus documentos. O sentido de criação da "Carta" era o de ser uma produção coletiva, um "polo aglutinador de intenções, de interações e de forças que caminham juntas" (MOTTA et al., 2012), para que se tornasse reveladora dos propósitos da rede e orientadora na reconstrução daqueles. A "Carta" tinha como finalidade, conceituar, com as equipes gestoras, os temas mais relevantes encontrados nos PPPs existentes nos estabelecimentos escolares do município, que dariam guarida à reconstrução dos mesmos. Os pontos debatidos e escolhidos, numa das formações realizadas foram: a) gestão democrática, b) clima escolar, c) convivência, d) processo ensino-aprendizagem, d) currículo, e) avaliação, f) metodologias. Para cada um desses tópicos, as equipes gestoras buscariam com suas unidades escolares e nos PPPs existentes nas escolas, as caracterizações existentes, traçando um conjunto de compreensões acerca dos significados presentes, numa dimensão de "qualidade negociada" - aquilo que não abrem mão para atingir os objetivos educacionais propostos para a reconstrução dos PPPs (COSTA; SZATKOSKI, 2015).

A esse respeito, destacamos a compreensão e deflagração do que se evidenciou por avaliação, como um conjunto de ações que se realizam em três âmbitos:

Institucional - onde se realiza um debate acerca da instituição, o que está efetivamente sendo conquistado pela escola e quais são os entraves para superá-los; avaliação do processo ensino-aprendizagem que considera importante o desenvolvimento do educando, mediante os vários acompanhamentos das etapas do seu desenvolvimento (registros e anotações diárias do professor, portfólios, provas, trabalhos (individuais e em grupo), apresentações, participações em eventos etc) em função das práticas pedagógicas vivenciadas e auto avaliação (DE TODOS) - aspectos qualitativos (realização das atividades; organização do material; assiduidade; pontualidade na entrega de trabalhos; pontualidade na entrada de seu período escolar; rendimento escolar, domínio de conteúdos). Além desses o trabalho coletivo e a escuta aos interesses e considerações de todos os envolvidos no processo. (SMED, 2017, p. 01).

A partir da "Carta", todas as escolas foram reconstruindo seus projetos. E, ao final do ano de 2017, quando, quase todas as unidades educativas já haviam construído seus PPPS, a mantenedora organizou uma audiência pública, com a participação de diversos segmentos da comunidade sapucaiense, acerca da pergunta "Que educação queremos para a nossa Rede 
Municipal de Ensino?"3 (SAPUCAIA DO SUL, 2017). O encontro, realizado em 18 de novembro de 2017, "contou com a participação de mais de 300 sapucaienses, entre professores, diretores, funcionários de escola, pais, estudantes e comunidade em geral" (SAPUCAIA DO SUL, 2017a). Os presentes, após conhecerem os objetivos do encontro e alguns dados referentes à educação da cidade (como, por exemplo, os índices do IDEB), compuseram dez grupos, com aproximadamente trinta pessoas, que livremente se dirigiram a cada um. Neles, discutiram e elaboraram uma síntese das reflexões feitas a partir de três questões: 1) Quais são as características socioculturais da cidade? 2) Quais são as perspectivas dos estudantes das escolas municipais para a vida? 3) Qual a educação que nossos estudantes necessitam?

Grosso modo podemos perceber que os participantes demonstraram uma preocupação com os aspectos para além da escola, essa compreendida numa perspectiva mais academicista, ou seja, aquela ideia que estaria voltada, meramente para a transmissão dos conhecimentos atribuídos à ciência. Ao contrário disso, propõem que a educação necessária é aquela que vai para além dos conhecimentos acadêmicos. Isso dialoga com a resposta dada à pergunta 1 , em que explicitaram o reconhecimento de ser a cidade um "dormitório", ou seja, um espaço onde as pessoas não se sentem partícipes, nem pertencentes dela. Têm ali suas casas, mas, de forma geral, divertem-se, trabalham, desenvolvem-se fora da cidade onde "dormem". Em função disso, a questão 2 caracterizou o estudante como sendo mais passivo, sem grandes perspectivas, posto que inserido num lugar/cotidiano onde a vida acontece longe dele, sentindo-se constantemente desestimulado e convidado a buscar noutros lugares, espaços culturais as opções de crescimento. A terceira questão, por sua vez, aponta para uma educação promotora do "protagonismo juvenil", para a transformação do futuro, adjetivada como uma educação “desafiadora", que incentive a formação de estudantes reflexivos e inseridos na contribuição de uma sociedade mais cidadã ${ }^{4}$. A partir desses movimentos, a mantenedora se pôs a construir seu projeto político-pedagógico.

Dito isso, acerca do cotidiano, propomos a realização de um conjunto de reflexões que pautam a avaliação, os processos avaliativos, a regulação e a qualidade, como promotoras de políticas educacionais, participativas, em favor de uma educação que comprometa-se com as viabilidades de uma sociedade do exercício da cidadania para todos e todas.

\footnotetext{
${ }^{3}$ Disponível em: http://www.sapucaiadosul.rs.gov.br/prefeitura-realiza-audiencia-publica-sobre-educacao/

${ }^{4}$ Tomamos o conceito de cidadania, aquele trazido por Silva e Azevedo (1999, p. 308) citando Severino: "homem só é plenamente cidadão se compartilha efetivamente dos bens que constituem os resultados de sua tríplice prática histórica, isto é, das efetivas mediações de sua existência. Ele é efetivamente cidadão se pode efetivamente usufruir dos bens materiais necessários para a sua existência física, dos bens simbólicos necessários para a sustentação de sua existência subjetiva e dos bens políticos para a sustentação de sua existência social [grifos nosso].
} 


\section{O lugar da avaliação no PPP}

O documento originário desse processo - o PPP da mantenedora, do qual nos dedicamos a analisar - discorre, nas suas 69 páginas, aspectos contextuais do município e de sua rede de educação, com 28 escolas e aproximadamente 16 mil alunos. Regida pelos princípios da responsabilidade, comprometimento, protagonismo, perseverança e ética. A rede municipal visa "proporcionar uma Educação de qualidade que desenvolva o protagonismo do indivíduo, por meio da valorização das suas potencialidades, para que consiga enfrentar desafios, utilizando os conhecimentos em prol de um sentido de vida." (SAPUCAIA DO SUL, 2018). $\mathrm{Na}$ sequência, são apresentadas as políticas educacionais e de participação popular, os fundamentos da construção do PPP da mantenedora, a "Carta de Princípios" e a proposta pedagógica da Rede. Após, são explicitados os funcionamentos de cada etapa de ensino e os projetos e programas em que as escolas e a mantenedora estão inseridas.

A avaliação aparece com um item vinculado ao próprio documento (avaliação do PPP da mantenedora), às etapas do ensino, às avaliações externas e ao desempenho do município frente a essas avaliações. Como características gerais dessas abordagens, cabe salientar a já citada preocupação com a avaliação em diferentes dimensões (institucional, ensinoaprendizagem e autoavaliação).

Dentro da apresentação do currículo pretendido pela rede, a avaliação ressurge, compreendida como "um recurso pedagógico que possibilita ao educador identificar as dificuldades do estudante e repensar a sua prática", aliada a um "planejamento flexível, para que possa atender as diversidades apresentadas no contexto educacional”' (p.33). Tais premissas são desdobradas nas especificidades da Educação Infantil, do Ensino Fundamental, da EJA e da Educação Especial. Nas páginas finais do PPP, o tema é retomado com a especificidade das avaliações externas, apresentando o censo escolar, o Sistema de Avaliação da Educação Básica (SAEB) e seus instrumentos (Prova Brasil, Provinha Brasil e ANA), e o desempenho da rede municipal nas avaliações do Governo Federal.

Na sequência, aparece o item avaliação interna. Ali é esclarecido que, desde 2015, é feito "o acompanhamento sistemático trimestral, de forma individual, das aprendizagens dos estudantes" (p. 66) em um processo que envolve escolas e mantenedora. Nesses momentos, os dados estatísticos são revistos e revisados com as equipes diretivas e pedagógicas, "a fim de ressignificar a trajetória dos estudantes, bem como refletir sobre as práticas pedagógicas dos professores" (p. 66), enfocando os aspectos de aprendizagem, permanência na escola, adequação idade-ano, encaminhamentos à rede de apoio, metodologias utilizadas, fatores de 
sucesso escolar e replanejamentos necessários. Importante dizer que grande parte das formações surgem dessas preocupações.

Em uma perspectiva mais ampliada, os indicadores obtidos também são analisados nos contextos específicos e gerais das escolas da rede, reforçando uma visão sistêmica e visando ao planejamento das ações pertinentes à mantenedora. As práticas de gestão escolar também são revisadas trimestralmente, analisando as dimensões pedagógica, gestão de equipe e ambiente escolar.

Tal abordagem, por parte do PPP de uma mantenedora, pode ser percebida como sucinta com relação à temática da avaliação. Tal brevidade, no entanto, não pode ser percebida como descaso ou como ausência de qualidade. Pelo contrário: a preocupação com a constância do item em todas as etapas de ensino revela a preocupação com a orientação à construção feita pelas escolas e todas as menções feitas sobre o assunto apresentam boa construção conceitual e/ou teórica.

A possibilidade suscitada por esta análise é que justamente o caráter destinado à avaliação pelo PPP é que acaba por configurar uma preocupação menos focalizada no desempenho frente às avaliações externas, ao contrário do que vem balizando as políticas educacionais estaduais e municipais nos últimos anos (GHISLENI, 2015; BONAMINO e SOUSA, 2012; SOUSA e ARCAS, 2010; WERLE, 2012; COSTA, 2010). Tal cenário, reconfigura os aspectos de regulação e de qualidade que funcionam como legitimadores da necessidade de padrões e de olhares externos.

\section{Os entendimentos e os conceitos}

Para além das importantes distinções técnicas no que concerne à avaliação, o princípio condutor de toda a análise aqui desenvolvida está vinculado à compreensão da avaliação como uma construção política. Tal acepção nos vincula a compromissos que aceitam e utilizam os rigores metodológicos imprescindíveis para a aplicação dos instrumentos afetos à operação do sistema, porém os compreende e os utiliza à luz da multiplicidade de fatores e de relações que são típicos da atividade educacional. Sem essa compreensão, corre-se o risco de delegar à avaliação um caráter finalístico totalmente descabido, que a desvincula das especificidades dos cenários que estão sendo avaliados.

Dentro desta mesma percepção, cabe-nos explicitar que o caráter político aqui apresentado tem a responsabilidade de trabalhar com dimensões contextuais e relacionais de 
maneira contínua, coletando e analisando exaustivamente os elementos vinculados a tendências, compreensões, escolhas realizadas, trajetórias percorridas, e posicionando-se criticamente diante disso.

Como nos lembra Dias Sobrinho:

Não podemos nos esquecer que as perguntas ou as questões realmente significativas estendem campos de dúvidas e significados abertos que nos impulsionam a sobre eles trabalhar. O caráter operativo da avaliação consiste, portanto, sobretudo em sua dimensão política. (DIAS SOBRINHO, 1996, p. 15)

As bases teóricas de sustentação aos conceitos foram buscadas em diferentes autores, justamente pela necessidade de múltiplos olhares a possibilitar o avanço no entendimento do campo da avaliação em larga escala. Para que se possa compreender a avaliação sob uma perspectiva macro analítica, que reconheça as estruturas sócio histórica e político-econômica como condicionantes das relações estabelecidas nas esferas institucionais, é que se propõe a mediação dos conceitos de regulação e qualidade.

\section{Regulação}

No campo educacional, latu sensu, e no campo da avaliação, de forma mais estrita, verifica-se uma disputa entre a autonomia e a regulação. A noção de autonomia é interessante de ser observada posto que, para além das diretrizes gerais que são estabelecidas, é importante analisar as construções específicas que são feitas pelos ambientes escolares.

O conceito de autonomia não pode ser limitado ao voluntarismo que normalmente o envolve. Hoje no Brasil, há legislação e mecanismos de gestão que circunscrevem a autonomia escolar de forma muito objetiva, determinando a possibilidade de obtenção de financiamentos, de vinculação a programas e a modelos de condução da gestão escolar que estão tanto ligados ao campo do público quanto ao do privado. Estando vinculados à obtenção de melhores resultados, alguns discursos de eficiência na gestão também encontram guarida na própria busca da autonomia, baseando-se no postulado de que, para fora de um modelo público que é considerado problemático, podem-se encontrar soluções de eficiência que se agregam a posturas autônomas e inovadoras. Dentro deste cenário, portanto, é importante percebermos a que o conceito de autonomia se refere. Nesta discussão, é sempre relevante ponderarmos sobre as palavras de Vieira (2007, p. 62), que nos lembra que "os graus de autonomia" de uma instituição "dizem respeito à sua história, a seu tamanho, ao seu corpo docente, à observância 
das diretrizes estabelecidas pelo sistema de ensino, seu desempenho e gestão de recursos".

A circunscrição da autonomia por modelos e diretrizes de gestão estabelece um dos papeis assumidos pela regulação. No caso da avaliação em larga escala, isso se evidencia no "recurso sistemático a referências internacionais", às 'lições que vêm de fora', [que] tem como principal função suprir, na argumentação política, a insuficiência ou deficiência dos exemplos nacionais (tradições, crenças, formas de organização).” (BARROSO, 2004, p. 22).

Barroso reafirma que assiste-se "a uma espécie de 'contaminação' internacional de conceitos, políticas e medidas postas em prática, em diferentes países, à escala mundial" (BARROSO, 2004, p. 22). Neste contexto, o autor constata 3 modelos de regulação: a regulação transnacional, o hibridismo da regulação nacional e a fragmentação da micro regulação local. Diante disso, estabelecem-se o desafio: gerir a multi-regulação através de mecanismos de metaregulação. Trata-se do estabelecimento de diretrizes capazes de romper a linearidade da mera aplicação específica das várias ordenações existentes para um determinado sistema.

Essa tendência para a multi-regulação produz a diversificação dos dispositivos e dos modos de coordenação de coordenação e controlo do sistema educativo. É o caso, por exemplo, do desenvolvimento da contratualização entre os diferentes níveis da administração; da emergência de estruturas intermediárias de regulação; do reforço da autonomia das escolas; da generalização dos dispositivos de avaliação; da passagem de uma 'regulação pela oferta' para uma 'regulação pela procura', na gestão do fluxo dos alunos; do estabelecimento de redes de relação entre as escolas e entre estas e outros parceiros; etc (BARROSO, 2004, p. 25).

Ainda de acordo com Barroso, a regulação do sistema educacional passa a constituir-se como um "sistema de regulações", configurando a meta-regulação do Estado "que permite não só equilibrar a ação das diversas forças em presença, mas também continuar a garantir a orientação global e a transformação do próprio sistema”. (BARROSO, 2004, p. 26). Isso implica, consequentemente, na mudança do papel do Estado, que tem de abrir mão da legitimidade única de ação do sistema educacional, e na abertura de muitas outras possibilidades de condução deste sistema. Esta pluralidade tanto pode abrir espaço para a participação mais ampliada de diferentes setores sociais, quanto também para o controle de diferentes esferas de gestão do sistema. A opção pelo último modelo tenderia tão somente a ampliar os mecanismos de avaliação externa, enfatizando a busca por resultados considerados mensuráveis e passíveis de comparação.

A regulação assume, assim, o caráter de estabelecer diretrizes mínimas de regramento e de organização das informações advindas dos instrumentos que são aplicados. A regulação, para além de mecanismos de controle, implica no estabelecimento de parâmetros de 
comparação e de confrontação, visando manter a legitimidade da aplicação dos instrumentos em diferentes cenários e a fidedignidade dos dados advindos desta aplicação.

A consagração de modelos avaliativos atrela-se à configuração mais contemporânea de Estado. Utilizando-se a mesma lógica de análise da formação do Estado nacional sob um prisma que alia movimentos políticos a intervenções de grupos econômicos e a determinações internacionais, pode-se perceber a preocupação atual com medições avaliativas como alicerçada em um modelo de Estado que atua na medida determinada pelo mercado. Tal percepção se encaixa tanto em uma relação com o ensino privado - na medida em que os atuais modelos avaliativos privilegiam, na sua maioria, performances de ordem classificatória e não formativa - quanto na relação com o ensino público, que acaba por adequar-se à mesma lógica classificatória e passa a ser verificado de acordo com os mesmos padrões que regem a lógica privada. É dentro deste cenário que a avaliação em larga escala "operou como componente da nova regulação permitindo ao Estado atentar mais para algumas coisas e menos para outras e alargar a presença reguladora da União na educação básica, com importantes implicações para as relações federativas." (FREITAS, 2007, p. 3. Grifos nosso).

Barroso (2004) propõe uma "nova" regulação do Estado, a partir da articulação entre o este, os professores profissionais e os pais dos alunos. Afinal, o que observou até aqui, foram três tipos de regulação, e todas não evidenciaram a qualidade da educação.

A regulação de tipo "burocrática-administrativa", realizada entre Estado e professores, a qual compreende a escola enquanto um "serviço do Estado". Centralizada nos técnicos da administração estatal, tem no diretor de escola seu mediador.

A regulação que denomina de "mercado", concretiza-se na parceria entre Estado e pais dos alunos. Tem como prerrogativa a diminuição do poder dos professores e sua participação. Além disso, há um ganho da classe média, pois é quem passa a escolher "as melhores" escolas e a fortalecer um comportamento de "consumidor", pois as escolas são introduzidas à concorrência entre si.

A "regulação comunitária", que rompe com o binômio Estado/Mercado ou Estado/privatizações, é a conjunção entre pais de alunos e professores. Nesta regulação parece mais possível haver uma democratização do ambiente escolar, haja vista a participação em conselhos de escola, projetos-político-pedagógicos ou intervenção social, porém, Barroso (2004) propõe o cuidado para que tal união não exclua alguma minoria existente no estabelecimento escolar. É por isso, que o autor propõe uma regulação que abarque os três elementos, a propósito de garantir, por meio da participação dos cidadãos a viabilidade de não haver uma centralização no Estado como se caracterizou sua função quando provedor, nem a 
regulação do mercado, a qual fortaleceu as privatizações e consolidou uma lógica de desigualdade entre seus usuários.

Em termos de configuração atual, o modelo econômico atua em um misto de regulação governamental com forças de mercado. No campo educativo, tal miscelânea assume especificidades, posto que este controle precisa de balizadores concretos. Daí a avaliação, como a medição numérica da qualidade. Esta medição gera pressões competitivas no mercado educativo, mas não pode ser entendida somente nesta dimensão. O controle sobre os resultados escolares não é mera lógica burocrática, ele engendra novas relações, regularidades e até mesmo ações que fogem do previsto.

Lima (2012) fala com muita clareza sobre o redimensionamento da ação do Estado, do sistema econômico e do sistema educacional, lembrando que novas proposições não significam o enfraquecimento da ação destas estruturas, mas sim a sua "reconversão"

[...] o sistema econômico e o sistema educativo continuam a revelar-se os principais agentes indutores da transição paradigmática, a qual não ocorre espontaneamente ou à margem de agendas políticas e objetivos de controle, mesmo se esse controle se apresenta, por vezes, difuso ou remoto. E isso, mesmo aceitando que o Estado-nação perdeu protagonismo e que novas formas de regulação e metarregulação de tipo transnacional e supranacional têm emergido. A centralidade do Estado-nação e dos governos nacionais não foi, contudo, afastada, mas antes reconvertida, permanecendo aqueles como relevantes atores na produção e reprodução de políticas educacionais e das condições para a sua execução, mesmo quando sob novas influências políticas e formas de organização, em contextos de reforma do Estado, através da erosão das suas responsabilidades de provisão de uma rede pública de escolas, estabelecendo parcerias várias com organizações da sociedade civil, delegando responsabilidades e contratualizando com o mercado (LIMA, 2012, p. 34).

Tensões causadas pela busca de melhorias ou de superação de padrões considerados insatisfatórios não podem ser entendidas somente sob uma única ótica. Temos de perceber que tanto os movimentos de resistência quanto os de mudança não ocorrem sem momentos de regulação. Como nos lembra Cóssio et al., (2010, p. 334), “a construção democrática implica na coexistência de regulação e emancipação". Isto significa dizer que as construções e as institucionalizações regulatórias são condição para a criação de modelos e criam as possibilidades de acompanhamento do que está se desenvolvendo. Para além do fato de nos posicionarmos contrários ou favoráveis ao que ocorre, é a existência de mecanismos reguladores mínimos que permite a construção deste posicionamento.

Freitas (2005) também contribui na discussão acerca da regulação ao trabalhar com o conceito de contra regulação. Fortemente ancorado em uma percepção educacional voltada para 
a prática e entendida como o campo de consolidação das políticas públicas, Freitas (2005) pauta-se pela ideia de "resistência propositiva" frente a regulações que não são fundamentais para a efetivação das políticas públicas - haja visto que, para o autor, a regulação, "no sentido amplo do termo, é vocação de toda política pública” (FREITAS, 2005, p. 913). A legitimidade da regulação, portanto, reside na luta por serviços públicos bem prestados, no cumprimento a direitos historicamente conquistados pela população. Ao lado disso, é fundamental que jamais confundamos as diferenças com desigualdades e os contextos analisados com situações que podem permanecer precárias. E que tenhamos clareza de que a qualidade, no setor público, não é optativa.

É baseada nesta proposição que se pretende compreender os resultados. A regulação per se, portanto, não é elemento suficiente para que os resultados apontados pelas fórmulas de acompanhamento não sejam submetidos a questionamentos.

A maneira como o conceito de regulação vem sendo utilizado largamente torna fundamental toda a reflexão que foi feita sobre esta noção e a tomada de uma posição sobre o conceito. Neste estudo, a noção de regulação, sempre é importante frisar, vincula-se a uma lógica de demonstrar, de forma transparente e democrática, o que vem sendo feito, tendo compreensão das nuances e das especificidades presentes nas construções educativas. Transformar a avaliação em um mecanismo único de responsabilização da gestão ou em instrumento de um suposto controle social reduz o processo educativo a uma mera transposição de resultados, acabando por transformar conquistas sociais como a transparência em empobrecidas sequências de resultados desligados de seus contextos e reais significados.

A criação de uma fórmula capaz de abarcar as condicionantes existentes em tal compreensão não é algo simples de ser feito. É justamente este nível de dificuldade que acaba engendrando a utilização de soluções mais simplificadas e/ou já experimentadas como o recurso possível. O caminho da ampliação da participação dos segmentos envolvidos na dinâmica educacional, de forma sistemática, organizada e propositiva parece ser o único caminho razoável para a criação de uma regulação com capacidade de articular a responsabilidade que o poder público possui com o bom andamento das políticas educacionais com o cumprimento deste papel de maneira efetiva. As premissas de regramentos e de informações generalizadas têm de ser percebidas como balizadoras e contextualizadoras, e não como definidoras de conduções e de resultados. 


\section{Qualidade}

Autores como Miguel Arroyo (2003) chamam a atenção para o fato do fracasso escolar ser percebido como resultado de uma produção individual (do aluno) insuficiente, e não como produto da organização escolar. E vai além, lembrando que "existe entre nós uma cultura do fracasso que dele se alimenta e o reproduz", apontando a qualidade da escola como condicionada à quantidade de exigências que não conseguem ser respondidas satisfatoriamente pelos alunos. Nesta lógica, o fracasso de uns acaba por valorizar a atuação de outros na escola, reiterando a sua forte cobrança com relação ao conhecimento sistematizado.

Há que pontuar também que se precisa de uma avaliação que vá muito além do estabelecimento dos limites entre a excelência e o fracasso. Entendê-la tão somente sob a ótica de um instrumento mensurador significa desconsiderar os múltiplos e preponderantes fatores ligados a esse processo e não lhe dar sentido futuro, de ação político-pedagógica. Como considera Perrenoud,

[...] a avaliação regula o trabalho, as atividades, as relações de autoridade e a cooperação em aula e, de uma certa forma, as relações entre a família e a escola ou entre profissionais da educação. Um olhar sociológico tenta constantemente considerar as lógicas do sistema que dizem respeito ao tratamento das diferenças e das desigualdades e, ao mesmo tempo, as lógicas dos agentes, que envolvem questões mais cotidianas, de coexistência, de controle, de poder." (PERRENOUD, 1999, p. 11).

Estudar a temática da avaliação significa repensar as atribuições históricas e culturais que foram incorporadas ao papel da escola, do professor e do aluno. Neste contexto, a avaliação em larga escala vai além de fatores eminentemente objetivos; implica situá-la em questões extremamente arraigadas, que entendem a escola como um lugar descolado de outras esferas sociais, atribuindo valor e peso ao que é internamente produzido sem juntar a esta equação outros elementos trazidos pelo sujeito que a produz. Isso também coloca em jogo uma ressignificação da organização escolar como promotora do sucesso ou do fracasso. E repensar a organização escolar significa avaliar internamente estruturas que estão há muito consolidadas e cuja modificação redundaria em alterações que vão para além da discussão prevista neste trabalho.

Se "os tradicionais fatores: o conteúdo transmitido, o transmissor e os métodos de transmissão perderam seu status de determinantes únicos e centrais"; e se "novas dimensões do processo escolar passaram a ser destacadas: a cultura escolar e a organização dos sistemas de ensino" (PERRENOUD, 1999, p. 13), o desafio atual seria perceber se e como a avaliação externa atualmente existente na educação básica brasileira efetivamente vem pautando 
alterações significativas na condução dos processos educativos, rompendo com a lógica do mero controle de resultados ou da padronização de sistemas de acompanhamento. Ou ainda, se serve apenas para diretrizes de financiamento ou para incutir mentalidade competitiva e servir como propaganda político-partidária ou pessoalizada, ou para justificar decisões mediante a evidência de uma estratificação educacional.

Avaliar significa destacar os avanços e os problemas, estabelecendo níveis de qualidade agregados a condições reais. A temática da qualidade sempre esteve presente nas discussões educacionais, mas tornou-se central, no Brasil, no decorrer dos anos 1990, quando um quadro de resolução do problema quantitativo abriu espaço para a ênfase na discussão qualitativa. Historicamente, a boa educação advinha do preceito da exclusividade, o que nos remete à instigante discussão de que a qualidade não pode ser para poucos e tampouco pode ser diferenciada por grupos.

Se no campo do consumo parece legítimo a qualidade estar mais fortemente agregada à exclusividade, entendemos que o mesmo não pode se dar no campo da educação em uma sociedade democrática. A exaustão da prerrogativa da exclusividade trouxe para a discussão o fato de que a escola não podia ser boa somente para poucos, mas teria de dar conta de ser igualmente boa para um público muito mais variado. A partir disso, outras possibilidades de encaminhamento tiveram de ser buscadas.

De início, isso passou por uma ênfase em investimentos nos insumos e na qualificação docente. Logo após a lógica dominante foi a da eficiência, apregoando a necessidade de fazerse mais pelo mínimo custo. Mais atualmente, reviveu-se a lógica dos investimentos, porém com o foco nos resultados. É daí que vêm as tentativas de como medi-los. É justamente neste contexto que se torna mais importante compreender as alterações que a compreensão e a dimensão da atuação estatal vêm sofrendo, bem como os mecanismos que vêm sendo buscados como resolução às questões vividas.

Em entrevista concedida em 2004, Stephen Ball nos apresenta duas equações que resultam em diferentes concepções de qualidade. A primeira delas trabalha com os elementos de ensino eficiente, bom desempenho nas provas e consequente ocorrência da aprendizagem. A segunda equação, por sua vez, tem o foco nos processos e nas condições gerais de ensino, resultando em uma perspectiva ampla de qualidade. Ball manifesta, na mesma entrevista, o seu descontentamento com a utilização de modelos importados de qualidade escolar, posto que eles evocam em uma visão reduzida do processo e têm fortes implicações no direcionamento do trabalho docente: 
De um lado, estudantes com bom desempenho são muito valorizados no mercado escolar. Por outro, estudantes com dificuldades de aprendizagem ou comportamento, que dificilmente poderiam contribuir de maneira fácil para o desempenho da escola, têm baixo valor no mercado educacional, tanto no Reino Unido quanto nos EUA, na Austrália e no Chile, por exemplo. No que se refere aos professores, há um efeito paralelo, uma vez que o trabalho do professor passa a ser reorientado pelo mercado. É esperado que os professores organizem e dirijam em função dos indicadores de resultado, que possam mostrar o bom desempenho da sua instituição. Dessa forma, passam a ser julgados em termos de sua contribuição na ampliação do valor de mercado da instituição a que pertencem. Esses julgamentos, em muitos casos, têm sido estendidos ao mercado interno que se desenvolve nas escolas, mudando as formas como os professores são avaliados e valorizados. De maneira crescente, os professores estão submetidos ao monitoramento, à vigilância, ao julgamento e às comparações realizados pelo sistema de mercado das escolas. Há pouca oportunidade e espaço em tais sistemas para eles perceberem ou debaterem sobre seus valores, que ficam à margem no sistema do mercado escolar, no qual tem importância apenas o que funciona para a instituição. Qualquer coisa a mais é apenas retórica. (BALL, 2004, p. 14)

Para Ball, o foco nos resultados gera a chamada "cultura da performatividade", com um "efeito insidioso na natureza do trabalho profissional" (BALL, 2004, p. 15), na medida em que "age em retroação sobre a prática para reorientá-la em direção a determinados resultados e valores" (Ibidem, p 15). Tal ação engendra o engessamento e o utilitarimo curricular, além da redução de toda a ação educativa e escolar a práticas e diretrizes voltadas bons aos desempenhos em avaliações pontuais.

\section{Considerações finais}

O que precisa ser constantemente reforçado é o fato de que as avaliações constituem-se em instrumentos capazes de fornecer informações tecnicamente precisas que nos orientem em função do melhor atendimento das dificuldades que se apresentam e da constante melhoria do que já se mostra viável. Se entendemos a educação como um fenômeno social, igualmente temos de entender a avaliação também como uma construção integrante deste fenômeno. Reforça-se: integrante do processo educativo, não o substituindo ou sobrepujando. Como nos lembra Dias Sobrinho (1996), "qualquer vinculação de qualidade a produtos ou serviços isolados e independentes de seus processos de produção, ou ainda, a funções restritivas, como a utilitarista, pode ser uma grave deturpação."

A ideia de construção de indicadores educacionais não está separada da proposta de haver referências que possam contribuir para um planejamento eficiente no sentido de ajudar a resolver os problemas que estão direta ou indiretamente relacionados à educação de forma mais 
assertiva. Afinal, como propõe Keinert (2009), os indicadores são "bases quantitativas para alcançar conclusões qualitativas" (p. 09). Serviram, num primeiro momento, única e exclusivamente para o planejamento técnico, sendo utilizados por especialistas para interpretarem os efeitos de uma determinada política (KEINERT, 2009).

Demo (1987) expressa os termos "qualidade formal" e "qualidade política" (p.112), distinguindo que "a primeira refere-se a instrumentos e a métodos e a segunda a finalidades e a conteúdos" (p. 112).

Os conceitos até aqui referidos relacionam-se fortemente com o contexto em que se insere a temática da avaliação. A utilização de cada um destes conceitos como ferramenta para a elucidação dos significados presentes nos discursos mais correntes sobre a avaliação pode auxiliar na quebra da resignação frente a um modelo que contém "um discurso de ênfase na qualidade [...], políticas de descentralização [...], avaliação de produto, resultados e um discurso de atendimento à pressão social [...]” (WERLE, 2010, p. 34)

Cury (2002), ao analisar a estrutura da educação básica no Brasil no período posterior à Constituição de 1988 e à LDB, garante centralidade a outra discussão relevante no que tange ao formato que a avaliação vem assumindo mais contemporaneamente. Ao se debruçar sobre alguns dos pressupostos legais da educação brasileira e aproximá-los da operacionalidade exigida pela lógica da avaliação, surge a inquietação sobre como vincular a premissa do regime colaborativo à cobrança por respostas que devem ser dadas pelas organizações locais do ensino quanto ao trabalho que vem sendo desenvolvido.

O problema é se a cooperação recíproca entre os sistemas, legalmente exigida para efeito de levar adiante o eixo da avaliação, está sendo efetivada tanto na montagem do processo avaliativo quanto na sua metodologia. Caso contrário, corre-se o risco de tornar os programas de avaliação novos paradigmas curriculares (do tipo currículo mínimo), inviabilizando a flexibilidade que a desburocratização legal permitiu em face da autonomia dos estabelecimentos escolares e refreando a criatividade estimulada pela lei. Nesse caso, a cooperação exigida em lei pode se transformar em formas sofisticadas de políticas centralizadoras. (CURY, 2002, p. 195-196).

O que se pretende, ao final deste artigo, é demonstrar de que forma as acepções acerca da avaliação passam por diferentes interpretações e/ou reconfigurações até chegar a uma configuração política que evidencia seguimento aos padrões estabelecidos, resistências, mudanças e alternativas. Trata-se, pois, de verificar como as construções políticas mais ou menos viáveis se efetivam nas práticas escolares e docentes cotidianas. O que interessa observar é o fato de uma construção político-pedagógica de extrema atualidade e vinculada a princípios participativos e de autonomia estabelece princípios avaliativos vinculados aos 
encaminhamentos da própria rede de ensino, sem vinculá-los de maneira direta aos resultados obtidos nas avaliações externas.

Tal situação pode revelar um reposicionamento frente à avaliação externa em larga escala, indo ao encontro de opções que supõem regulações mais autônomas e legítimas e concepções de qualidade baseadas nos contextos onde o trabalho pedagógico é desenvolvido. Ao final dessa análise, compreende-se que tais encaminhamentos revestem-se de legitimidade e podem, nos seus processos de elaboração e de efetivação, inaugurarem uma retomada de processos mais políticos que sejam condutores e possibilitadores de um trabalho pedagógico qualificado e coerente.

\section{REFERÊNCIAS}

ARROYO, M. G. Fracasso-sucesso: o peso da cultura escolar e do ordenamento da educação básica. In: ABRAMOWICZ, A.; MOLL, J. Para além do fracasso escolar. Campinas: Papirus, 2003.p. 11-27.

BALL, S. Entrevista. Educação em Revista, Belo Horizonte, v. 40, p. 11-26, dez. 2004. Entrevista concedida a Lucíola Licínio C.P. Santos.

BARROSO, J. Os novos modelos de regulação das políticas educativas na Europa: da regulação do sistema a um sistema de regulações. Educação em Revista, Belo Horizonte, v. 39, p. 19-28, jul. 2004.

BONAMINO, A.; SOUSA, S. Z. Três gerações da avaliação na educação básica no Brasil: interfaces com o currículo da/na escola. Educação e Pesquisa, São Paulo, v. 38, n. 2, p. 373388, abr./jun. 2012.

COSTA, D. M. Tensões e influências no contexto das políticas de avaliação em larga escala: uma análise da participação das confederações de trabalhadores em educação do Brasil e da Argentina. 2010. 243 f. Tese (Doutorado em Educação) - Programa de PósGraduação em Educação, Universidade do Vale do Rio dos Sinos (UNISINOS), São Leopoldo, 2010.

COSTA, D. M. Diálogos entre avaliação e o estabelecimento escolar aprendente: um princípio de insubordinação. In: WERLE, F. O. C. Avaliação em larga escala: foco na escola. São Leopoldo/RS: Oikos; Brasília: Liber Livros. 2010. p. 203-216.

COSTA, D. M.; SZATKOSKI, L. Possibilidade de avanço democrático a partir das políticas educacionais: olhares sobre a gestão municipal de Jacareí. Revista Brasileira de Política e Administração da Educação, Porto Alegre, v. 31, n. 1, p. 159-175, jan./abr., 2015.

CÓSSIO, M. de F.; et al. Gestão educacional e reinvenção da democracia: questões sobre regulação e emancipação. Revista Brasileira de Política e Administração da Educação, Porto Alegre, v. 26, n. 2, p. 325-344, maio/ago., 2010. 
DIAS SOBRINHO, J. Avaliação institucional: marcos teóricos e políticos. Avaliação, v. 1, n. 1, p. 15-24, 1996.

FREITAS, D. N. T. de. A avaliação da educação básica no Brasil. Campinas: Autores Associados, 2007.

FREITAS, L. C. de. Qualidade negociada: avaliação e contra regulação na escola pública. Educação e Sociedade, Campinas, v. 26, n. 92, p. 911-933, Especial, out. 2005.

GHISLENI, A. C. Efeitos da política nacional de avaliação em larga escala na gestão e na prática pedagógica do Sistema Municipal de Porto Alegre (2005-2013). 2015. 172 f. Tese (Doutorado em Educação) - Programa de Pós-Graduação em Educação, Universidade Federal do Rio Grande do Sul (UFRGS), Porto Alegre, 2015.

LIMA, L. C. Aprender para ganhar, conhecer para competir. São Paulo: Cortez, 2012.

MOTTA, C. G. L. da. et al. Carta escolar: instrumento de planejamento coletivo. In: GADOTTI, M.; ROMÃO, J. E. Autonomia da escola: princípios e propostas. $7^{\text {a }}$ ed. São Paulo: Cortez, 2012. p. $57-73$.

PERRENOUD, P. Avaliação: da excelência à regulação das aprendizagens. Entre duas lógicas. Porto Alegre: Artmed, 1999.

SMED. Carta de Princípios. Sapucaia do Sul - documento. 2017.

SAPUCAIA DO SUl. Audiência Pública. 2017. Disponível em http://www.sapucaiadosul.rs.gov.br/prefeitura-realiza-audiencia-publica-sobre-educacao/. Acesso em: 28 jun. 2018.

SAPUCAIA DO SUL. Audiência Pública. 2017a. Disponível em, http://www.sapucaiadosul.rs.gov.br/educacao-basica-foi-tema-de-audiencia-publica/. Acesso em: 28 jun. 2018.

SOUSA, S. Z.; ARCAS, P. H. Implicações da avaliação em larga escala no currículo: revelações de escolas estaduais de São Paulo. Educação: Teoria e Prática, Rio Claro, v. 20, n. 35, p. 181-199, jul./dez., 2010.

WERLE, F. O. C. Avaliação em larga escala: questões polêmicas. Brasília: Líber, 2012.

\section{Como citar este artigo:}

GHISLENI, Ana Cristina; COSTA, Daianny Madalena. A avaliação revisitada: novos espaços do político e do pedagógico na gestão educacional. Revista Ibero-Americana de Estudos em Educação, Araraquara, v. 14, n. 3, p. 956-972, jul./set., 2019. e-ISSN: 1982-5587. DOI: 10.21723/riaee.v14i3.11830

Data de Submissão: 17/10/2018

Aceite em: 04/12/2018
Revisões requeridas: $16 / 11 / 2018$

Publicado em: 25/03/2018 